\title{
Florística, fitossociologia e modelagem da distribuição diâmétrica em um fragmento de Caatinga em São Mamede-PB
}

\author{
Felipe Silva de Medeiros ${ }^{1 *}$, Mailson Pereira de Souza², Clebson Lima Cerqueira ${ }^{3}$, Allyson \\ Rocha Alves ${ }^{4}$, Marina dos Santos Souza ${ }^{5}$, Cesar Henrique Alves Borges ${ }^{6}$
}

\begin{abstract}
RESUMO: Objetivou-se realizar um estudo florístico e fitossociológico, ajustar e selecionar funções de densidade probabilidade para expressar a distribuição diamétrica do componente florestal lenhoso em um fragmento de Caatinga localizada na Fazenda Massapê, município de São Mamede-PB. Foi realizado inventário de todos os indivíduos arbustivos arbóreos vivos com CAP $\geq 6 \mathrm{~cm}$. As variáveis registradas foram: CAP, altura total e nome popular de todos os indivíduos mensuráveis nas unidades amostrais. No levantamento realizado no fragmento de Caatinga foram amostrados 304 indivíduos vivos, pertencentes a 8 famílias, 13 espécies e 13 gêneros. Os valores encontrados para Densidade Total e Área Basal foram, respectivamente, 950 ind.ha $\mathrm{e}^{-1} \mathrm{e} 6,33 \mathrm{~m}^{2} \mathrm{ha}^{-1}$. As famílias mais ricas em número de espécies e indivíduos foram a Fabaceae e Euphorbiaceae. As espécies que assumem maior importância na área de estudo sob os aspectos fitossociológicos foram Pocianella pyramidalis (Tul.) L.P.Queiroz, Aspidosperma pyrifolium Mart., Mimosa tenuiflora (Willd.) Poir., Combretum leprosum Mart., Jatropha molissima (Pohl.) Baill., Ximenia intermedia (Chodat \& Hassl.) De Filipps. A função Weibull com três parâmetros apresentou aderência para todas as espécies estudadas e para as de maior (VI) gerando estimativas consistentes e pode ser indicada para descrever a distribuição diamétrica e auxiliar na tomada de decisões sobre o manejo e conservação das espécies.

Palavras-chave: estrutura, manejo florestal, modelos probabilísticos.
\end{abstract}

Floristica, phytosociology and modeling of diametric distribution in caatinga fragment in São Mamede-PB.

ABSTRACT: The objectives of the study were to perform a floristic and phytosociological study, to adjust and select probability density functions to express the diametric distribution of the woody component in a Caatinga fragment located at Fazenda Massapê, São Mamede-PB municipality. An inventory of all live arboreal individuals with CAP $\geq 6$ $\mathrm{cm}$ was performed. The variables recorded were CAP, total height and popular name of all measurable individuals in the sample units. In the survey carried out on the Caatinga fragment, 304 living individuals belonging to 8 families, 13 species and 13 genera were sampled. The values found for Total Density and Basal Area were, respectively, 950 ind.ha1 and $6.33 \mathrm{~m} 2 \mathrm{ha}-1$. The families richest in number of species and individuals were Fabaceae and Euphorbiaceae. The species that are most important in the study area under phytosociological aspects were Pocianella pyramidalis (Tul.) LPQueiroz, Aspidosperma pyrifolium Mart., Mimosa tenuiflora (Willd.) Poir., Combretum leprosum Mart., Jatropha molissima (Pohl.) Baill, Ximenia intermedia (Chodat \& Hassl.) De Filipps. The Weibull function with three parameters presented adherence for all the species studied and for the larger ones (VI) generating consistent estimates and can be indicated to describe the diametric and auxiliary distribution in the decision making on the management and conservation of the species.

Keywords: structure, forest management, probabilistic models.

\section{INTRODUÇÃO}

O Nordeste do Brasil compreende uma área de $1.554,744 \mathrm{~km}^{2}$. Isso corresponde a $18,3 \%$ do território do país, onde o semiárido nordestino está inserido com uma área de $982.56,3 \mathrm{~km}^{2}$, ou seja, $63,2 \%$ do território nordestino. No semiárido nordestino dentre os biomas existentes predomina a Caatinga com uma área de $844.453 \mathrm{~km}^{2}$ que se estende pelos estados do CE, BA, PB, PE, PI, RN, $\mathrm{AL}, \mathrm{SE}$, além de uma pequena parte do território de
MG e do MA. Rico em biodiversidade o bioma abriga 178 espécies de mamíferos, 591 de aves, 177 de répteis, 79 espécies de anfíbios. Além disso, cerca de 27 milhões de pessoas vivem na região, sendo considerada a mais necessitada e dependente dos recursos para sobreviver (BRASIL, 2017). É considerado um bioma único pelas suas paisagens, relativa riqueza biológica e grande número de espécies endêmicas, 241 de peixes e 221 abelhas.

Recebido em 20/07/2017; Aceito para publicação em 07/06/2018

${ }^{1}$ Universidade Federal de Campina Grande.

${ }^{2}$ Universidade Federal Rural do Rio de Janeiro

${ }^{3}$ Universidade Federal do Mato Grosso

${ }^{4}$ Universidade Federal Rural do Semi-Árido

${ }^{5}$ Universidade Federal do Piauí

${ }^{6}$ Universidade Federal Rural de Pernambuco

*E-mail: fsmedeiros.eng@gmail.com 
Entretanto, apesar de ser um bioma com alta diversidade de espécies, é floristicamente pobre em comparação com florestas tropicais úmidas (MONTEIRO et al., 2015).

A região na qual a vegetação da caatinga se encontra é marcada por longos períodos de estiagem e pela alta heterogeneidade de solo. De acordo com Rodal et al. (2008), sua vasta cobertura vegetal é, em sua maioria, determinada e influenciada pelo clima, relevo e embasamento geológico. Geralmente apresenta-se com uma forma que pode variar entre herbácea, arbustiva ou arbórea, podendo ser aberta ou densa, decídua, na época seca e verde na estação das chuvas, e geralmente com cactáceas e bromeliáceas (MOREIRA et al., 2007).

Os ecossistemas do bioma Caatinga apresentamse bastante alterados com a substituição da vegetação nativa por cultivos e pastagens, utilizando metodologias rudimentares no preparo do solo como o desmatamento seguido pela queimada, prejudicando a manutenção das populações da fauna silvestre, qualidade da água e o equilíbrio do clima e do solo.

Com base no exposto, os estudos fitossociológicos se tornam uma ferramenta imprescindível para a determinação das espécies florestais. Através desses estudos é possível determinar graus de hierarquização entre espécies e avaliar a carência de medidas voltadas para a preservação e conservação das unidades florestais (CHAVES et al., 2013; BULHÕES et al., 2015). Além disso, os estudos fitossociológicos fornecem dados para a realização de planos de manejo florestal sustentáveis, estudos de impactos ambientais, restauração florestal, projetos de recuperação de áreas degradadas, indicando o potencial do uso de determinada espécie, seja para lenha, carvão, estacas, mourões, entre outras.

Neste contexto, o desenvolvimento de estudos que visam nortear tomadas de decisões por meio da análise da estrutura do componente florestal é sem dúvida imprescindível para conservação e uso dos recursos naturais de forma sustentável. Nessa ótica, a análise da distribuição diamétrica em florestas inequiâneas atrelada aos estudos fitossociológicos possibilita melhor conhecimento e entendimento das espécies que compõem a floresta, possibilitando um melhor planejamento para o estabelecimento de estratégias adequadas para a conservação e manejo (ALVES et al., 2017).

Diversos autores têm estudado a florística, fitossociologia e distribuição diamétrica da Caatinga (CALIXTO JÚNIOR e DRUMOND, 2014; ALVES et al. 2013; HOLANDA et al. 2015). Já trabalhos com o emprego de funções de densidade probabilidade para descrever a distribuição diamétrica da caatinga e suas espécies arbóreas ainda são escassos, como o trabalho de Marangon et al. (2016), pioneiro para tal tipologia florestal.

Neste contexto, objetivou-se, realizar um estudo florístico, fitossociológico e ajustar e selecionar funções de densidade probabilidade para expressar a distribuição diamétrica do componente florestal lenhoso em um fragmento de Caatinga.

\section{MATERIAL E MÉTODOS \\ Localização e descrição da área de estudo}

A pesquisa foi realizada em fragmento florestal de caatinga com área total de 50,0 ha que está localizada na Fazenda Massapê, situada no município de São Mamede, Estado da Paraíba, Mesorregião do Sertão e Microrregião Patos. Este município limita-se ao norte com Ipueira (RN) e Várzea, leste com Várzea e Santa Luzia, sul com Areia de Baraúnas, Passagem e Quixaba, e, oeste, com Patos e São José de Espinharas, conforme o Serviço Geológico do Brasil (CPRM), (BRASIL, 2005), localizado entre as coordenadas geográficas Longitudes 98210000 e 9251000 e Latitudes 564300 e 567600 SIRGAS 2000 (Figura 01).

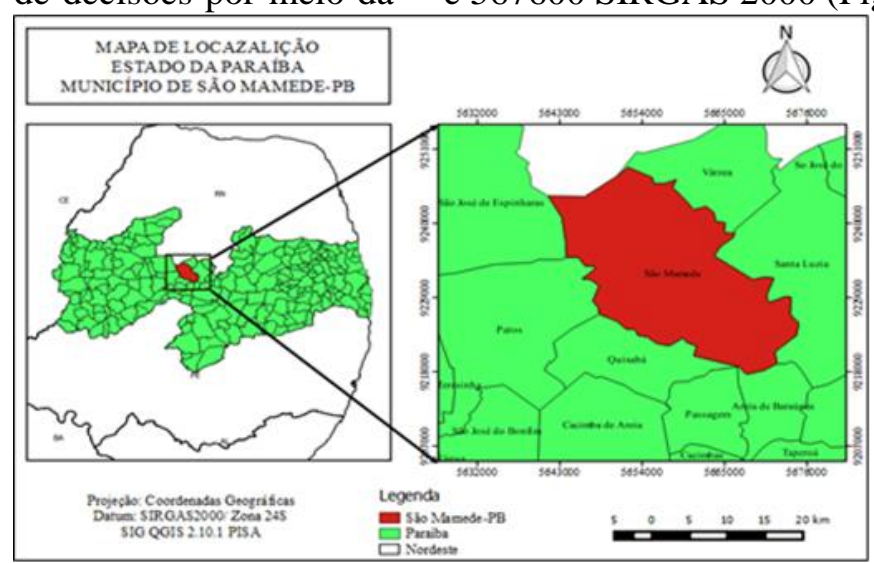

Figura 01 -Localização do município de São Mamede, Paraíba, Brasil.

O clima da região é o Tropical Semiárido, com chuvas de verão, na qual o período chuvoso se inicia em novembro com término em abril, com uma precipitação média de 431,8 mm (BRASIL, 2005). Segundo Alvares et al., (2014) essa região apresenta clima Semiárido (Bsh), ou seja, quente e seco com 
chuvas de verão. Quanto ao tipo de solo encontrado no município, nos Patamares Compridos e Baixas Vertentes do relevo suave ondulado ocorrem os Planossolos, mal drenados, fertilidade natural média e problemas de sais (BRASIL, 2005).

\section{Amostragem}

Para coleta dos dados foi adotado o sistema de Amostragem Aleatória Simples (SOARES et al., 2009), onde foram sorteadas e alocadas 8 unidades amostrais de $20 \mathrm{~m} \times 20 \mathrm{~m}\left(400 \mathrm{~m}^{2}\right)$, totalizando $3200 \mathrm{~m}^{2}$ de área amostral.

Nas unidades amostrais, foram inventariados todos os indivíduos florestais arbustivos arbóreos vivos que apresentaram Circunferência a Altura do Peito maior ou igual a seis centímetros (CAP $\geq 6$ $\mathrm{cm})$. As variáveis medidas e registradas foram: Circunferência a Altura do Peito (CAP), mensurada com fita métrica graduada em centímetros (precisão de $0,5 \mathrm{~cm}$ ), altura total (HT), com auxílio de vara graduada em metros (precisão de $0,50 \mathrm{~m}$ ) e nome popular de todos os indivíduos mensuráveis nas unidades amostrais. Para determinar o número ótimo de parcelas amostrais, foi utilizado o método de estabilização da curva do coletor (Figura 02).

\section{Florística e fitossociologia}

As espécies florestais foram identificadas in loco por meio da observação de seus aspectos dendrológicos (formato da copa, folhagem, casca e caule), quando possível, por coleta de material botânico para herborização e posterior identificação e/ou confirmação dos nomes científicos por consultas à literatura especializada (LORENZI, 2002a, 2002b; SAMPAIO et al., 2005; GAMARRAROJAS et al., 2010; SIQUEIRA FILHO et al., 2009; FORZZA et al., 2012; SILVA et al., 2010; LIMA, 2012; MAIA, 2012) e especialistas. Para classificação das espécies foi adotado o sistema
APG III (2011), sendo classificadas até o nível de família. Em posse dos dados foram avaliados os parâmetros fitossociológicos da estrutura horizontal das espécies amostradas (FELFILI e REZENDE, 2003), a diversidade florística de espécies através do Índice de Shannon-Weaver (H'), de dominância de Simpson (C) e equabilidade de Pielou (J').

Para análise da estrutura hipsométrica foi confeccionado um histograma com o número de indivíduos por classe de altura, sendo que o centro da primeira classe foi $1,5 \mathrm{~m}$ e intervalo fixo de $1,5 \mathrm{~m}$ entre as classes. Para a estrutura diamétrica também foi feito um histograma relacionando o número de indivíduos por classe de diâmetro com o DAP (diâmetro a altura do peito) inicial de $2,0 \mathrm{~cm}$ e intervalos de 2,0 cm entre as classes.

\section{Distribuição diamétrica}

A distribuição diamétrica foi realizada por meio do ajuste de funções de densidade de probabilidade. A distribuição diamétrica é a frequência do diâmetro a altura do peito (DAP) apresentado em um histograma, podendo apresentar diferentes formas, dentre elas a exponencial negativa, unimodal, bimodal ou irregular, variando de acordo com a estrutura da floresta. Estas distribuições podem assumir várias formas de acordo com os coeficientes, ajustando-se aos dados de florestas nativas e plantadas como comprovado em estudos realizados por diversos autores como, (ORELLANA et al., 2014; KUCHLA et al., 2015; SANTOS et al., 2016; MARANGON et al., 2016).

Neste estudo adotou se como procedimento padrão o ajuste das funções Normal, log-normal, Gama e Weibull com 2 e 3 parâmetros (Tabela 01). As funções de densidade probabilísticas ajustadas são todas de uso frequente na modelagem da distribuição diamétrica de florestas nativas e plantadas.

Tabela 01 - Funções densidade de probabilidade ajustada para o remanescente de Cerrado.

\begin{tabular}{|c|c|c|}
\hline Modelo & $\begin{array}{r}\text { FDP } \\
\end{array}$ & Parâmetro \\
\hline Normal & $f(x)=\frac{1}{\sigma * \sqrt{2 \pi}} e^{\left[-\frac{1}{2} *\left(\frac{(x-\mu)^{2}}{\sigma^{2}}\right)\right]}$ & $\begin{array}{l}\mu \\
\sigma \\
\end{array}$ \\
\hline Lognormal & $f(x)=\frac{1}{\sigma * \sqrt{2 \pi}} e^{\left[-\frac{1}{2} *\left(\frac{(\ln x-\mu)^{2}}{\sigma^{2}}\right)\right]}$ & $\begin{array}{l}\mu \\
\sigma \\
\end{array}$ \\
\hline Weibull 2P & $f(x)=\frac{c}{b}\left(\frac{x}{b}\right)^{c-1} e^{-\left(\frac{x}{b}\right)^{c}}$ & $\begin{array}{l}\beta \\
\gamma\end{array}$ \\
\hline Gama & $f(x)=\frac{(x-\alpha)^{\gamma-1} e^{-\frac{(x-\alpha)}{\beta}}}{\beta^{\gamma} \Gamma(\gamma)}$ & $\begin{array}{l}\alpha \\
\beta \\
\gamma \\
\end{array}$ \\
\hline Weibull 3P & $f(x)=\frac{\gamma}{\beta}\left(\frac{x-\alpha}{\beta}\right)^{\gamma-1} e^{-\left(\frac{x-\alpha}{\beta}\right)^{\gamma}}$ & $\begin{array}{l}\alpha \\
\beta \\
\gamma\end{array}$ \\
\hline
\end{tabular}

*Em que: $\mathrm{f}(\mathrm{x})=$ função de densidade da variável $\mathrm{x}$; $\mathrm{x}$ - diâmetro do centro de classe; $\mu$ - média aritmética; $\sigma$ - desvio padrão; $\sigma^{\wedge} 2=$ variância da variável aleatória $x ; \pi$ - é a constante "pi"; $\alpha=$ Parâmetro de locação; $\beta=$ parâmetro de escala, $\gamma=$ parâmetro de forma.

Foram ajustadas funções densidade de as três espécies que apresentaram maior valor de probabilidade para toda a comunidade arbórea e para importância (VI). Os dados de (DAP) observados 
foram agrupados em classes de diâmetro com amplitude de $3 \mathrm{~cm}$, de acordo com o método proposto por Sturges (1926). Gerando-se, assim, as estimativas em cada classe de diâmetro para cada método de ajuste das funções densidade de probabilidade utilizada.

Os parâmetros das funções de densidade probabilidade e posterior estimativa do número de árvores em cada classe foi realizado com auxílio do software R (R Core Team 2015), por meio do pacote MASS. Os coeficientes da distribuição Normal ficaram definidos com a média e o desvio padrão dos dados originais. Já os coeficientes da LogNormal, com a média e a variância dos logaritmos dos dados originais.

Existem diferentes maneiras para analisar a eficiência dos modelos probabilísticos e a comparação entre eles. Neste trabalho optou-se pelo Critério de Informação de Akaike (1973). O referido critério mede a distância do modelo "verdadeiro" desconhecido ao modelo em questão que gerou os dados, ou seja, quanto menor a distância, mais adequado é o modelo (BURNHAM; ANDERSON 2002).

\section{RESULTADOS E DISCUSSÃO}

A suficiência amostral, demonstrada pela curva coletora (Figura 02) somente estabilizou a partir da sexta parcela amostrada, onde houve uma redução no número de novas espécies descobertas, ou seja, aos $2400 \mathrm{~m}^{2}$, cujo $100 \%$ do número das espécies inventariadas já haviam sido registradas. A partir desse ponto houve uma estagnação no número de espécies, indicando ser satisfatória a amostragem realizada para a área em estudo, de modo a atingir o mínimo de parcelas a ser utilizadas para caracterização da composição florística do fragmento estudado.

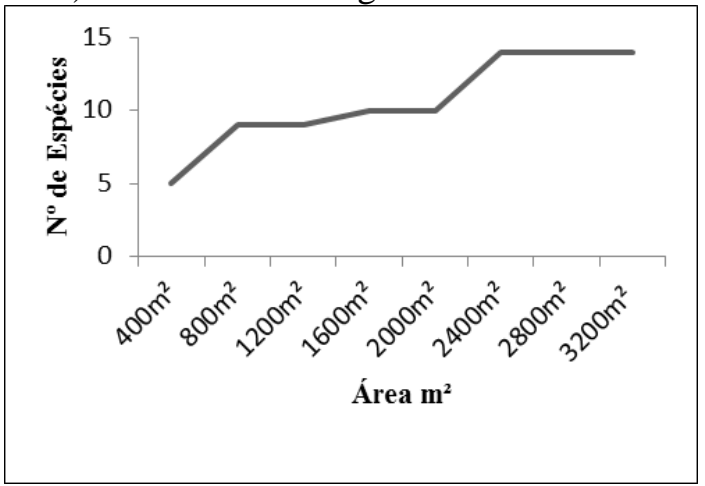

Figura 02-Representação gráfica da suficiência amostral das espécies inventariadas em um fragmento de Caatinga na Fazenda Massapê, município de São Mamede-PB

No levantamento realizado no fragmento de caatinga foram amostrados 304 indivíduos vivos, pertencentes a 8 famílias, 13 espécies e 13 gêneros (Tabela 02). Os valores apresentados para Densidade Total e Área Basal foram, respectivamente, 950 ind.ha ${ }^{-1}$ e $6,33 \mathrm{~m}^{2} \mathrm{ha}^{-1}$, sendo inferiores aos valores apresentados na maioria dos levantamentos aqui comparados, como os observado por Alves et al. (2013). No entanto, apresentou uma superioridade em relação a alguns levantamentos, ganhando destaque sobre Calixto Junior e Drumond, (2014) e Ferraz et al. (2013). Torna-se importante ressaltar que no levantamento observou-se um grande número de indivíduos mortos o que corrobora com características de um ambiente em estágio sucessional secundário, onde a presença de espécies de sucessão secundária é bem mais marcante.

Tabela 02 - Listagem das espécies inventariadas em fragmento de caatinga na Fazenda Massapê, município de São Mamede-PB.

\begin{tabular}{llll}
\hline Família & Espécies & Nome popular & Hábito \\
\hline Olacaceae & Ximenia intermedia (Chodat \& Hassl.) De Filipps & Ameixa & Arbusto \\
Fabaceae & Anadenanthera colubrina (Vell.) Brenan & Angico & Árvore \\
Fabaceae & Pocianella pyramidalis (Tul.) L.P.Queiroz & Catingueira & Árvore \\
Euphorbiaceae & Cnidoscolus quercifolius Pohl & Favela & Árvore \\
Burseraceae & Amburana cearensis Allemão & Cumaru & Árvore \\
Rhamnaceae & Ziziphus joazeiro Mart. & Juazeiro & Árvore \\
Fabaceae & Mimosa tenuiflora (Willd.) Poir. & Jurema P. & Árvore \\
Euphorbiaceae & Croton sonderianus Muell. Arg. & Marmeleiro & Árvore \\
Combretaceae & Combretum leprosum Mart. & Mufumbo & Arbusto \\
Bignoniaceae & Tabebeuia impetiginosa var. lepidota (Bureau) & Pau D'arco & Árvore \\
Apocynaceae & Aspidosperma pyrifolium Mart. & Pereiro & Árvore \\
Euphorbiaceae & Jatropha molissima (Pohl.) Baill & Pinhão B. & Arbusto \\
Fabaceae/Caesapinoidea & Bauhinia cheilantha (Bong.) Steud. & Mororó & Arbusto \\
- & sp & & - \\
\hline
\end{tabular}


As famílias que apresentaram maiores quantidades de espécies foram Fabaceae e Euphorbiaceae, cada uma com 3 espécies. Juntas estas duas famílias contabilizaram cerca de $40 \%$ do total de espécies presentes no fragmento, enquanto $77,7 \%$ das famílias apresentaram apenas um idivíduo. Segundo Ferraz et al., (2013); Calixto Junior e Drumond, (2014); Leite et al., (2015), essas duas famílias apresentam o maior número de espécies em diversos levantamentos florísticos com espécies lenhosas na caatinga, corroborando com os dados verificados neste estudo. $\mathrm{O}$ total de espécies levantadas é considerado baixo, quando comparado com levantamentos realizados nos diferentes tipos de vegetação caducifólias do semiárido, nos quais o número de espécies varia entre 16 e 52 (CALIXTO JUNIOR E DRUMOND, 2014; FERRAZ et al., 2013; LEITE et al., 2015; ALVES et al., 2013;
LIMA; COELHO, 2015). Essa perda de diversidade pode ser explicada pelo uso e ocupação do solo dado a este fragmento nos últimos anos, onde as características do cultivo de algodão ainda são bastante marcantes no local de estudo, por isso acredita-se que a perca de diversidade foi uma consequência da exploração desordenada e intensificada do solo.

As espécies que detiveram o maior número de ocorrências consideradas dominantes na fisionomia foram: Pocianella pyramidalis, Aspidosperma pyrifolium, Mimosa tenuiflora, Amburana cearensis, totalizando $90 \%$ da densidade total do fragmento estudado. Estas mesmas espécies obtiveram as maiores frequências relativas confirmando, assim, a predominância de ambas no fragmento (Tabela 03).

Tabela 03-Parâmetros fitossociológicos das espécies amostradas em fragmento de caatinga na Fazenda Massapê, município de São Mamede-PB.

\begin{tabular}{|c|c|c|c|c|c|c|c|c|}
\hline Espécies & NI & DA & DR & FA & FR & DoA & DoR & IVI \\
\hline Pocianella pyramidalis (Tul.) L. P. Queiroz & 131,00 & 409,00 & 43,09 & 100,00 & 17,39 & 2,91 & 46,01 & 35,49 \\
\hline Aspidosperma pyrifolium Mart. & 103,00 & 322,00 & 33,88 & 100,00 & 17,39 & 1,86 & 29,37 & 26,88 \\
\hline Mimosa tenuiflora (Willd.) Poir. & 36,00 & 113,00 & 11,84 & 87,50 & 15,22 & 1,13 & 17,83 & 14,96 \\
\hline Combretum leprosum Mart. & 5,00 & 16,00 & 1,64 & 50,00 & 8,70 & 0,03 & 0,52 & 3,62 \\
\hline Jatropha molissima (Pohl.) Baill & 4,00 & 13,00 & 1,32 & 37,50 & 6,52 & 0,03 & 0,48 & 2,77 \\
\hline Amburana cearensis Allemão & 5,00 & 16,00 & 1,64 & 25,00 & 4,35 & 0,14 & 2,25 & 2,75 \\
\hline Croton sonderianus Muell. Arg. & 3,00 & 9,00 & 0,99 & 37,50 & 6,52 & 0,02 & 0,33 & 2,61 \\
\hline Ximenia intermedia (Chodat \& Hassl.) De Filipps & 3,00 & 9,00 & 0,99 & 37,50 & 6,52 & 0,02 & 0,27 & 2,59 \\
\hline Bauhinia (Bong.) Steud. & 6,00 & 19,00 & 1,97 & 25,00 & 4,35 & 0,04 & 0,58 & 2,30 \\
\hline Morfoespécie 1 & 4,00 & 13,00 & 1,32 & 25,00 & 4,35 & 0,05 & 0,73 & 2,13 \\
\hline Cnidoscolus quercifolius Pohl & 1,00 & 3,00 & 0,33 & 12,50 & 2,17 & 0,08 & 1,21 & 1,24 \\
\hline Anadenanthera colubrina (Vell.) Brenan & 1,00 & 3,00 & 0,33 & 12,50 & 2,17 & 0,01 & 0,23 & 0,91 \\
\hline Ziziphus joazeiro Mart. & 1,00 & 3,00 & 0,33 & 12,50 & 2,17 & 0,01 & 0,14 & 0,88 \\
\hline $\begin{array}{l}\text { Tabebeuia impetiginosa var. lepidota (Bureau) } \\
\text { Toledo }\end{array}$ & 1,00 & 3,00 & 0,33 & 12,50 & 2,17 & 0,00 & 0,05 & 0,85 \\
\hline Total Geral & 304,00 & 950,00 & 100,00 & 575,00 & 100,00 & 6,33 & 100,0 & 100,0 \\
\hline
\end{tabular}

Pocianella pyramidalis foi à espécie de maior destaque, por apresentar maior número de indivíduos e, consequentemente, o maior valor de densidade relativa $(43,09 \%)$ e a maior frequência relativa $(17,39 \%)$. Além disso, obteve o maior valor de dominância relativa, tornando-se, assim, a primeira espécie com maior IVI da população amostrada. É de suma importância ressaltar que o grande número de indivíduos dessa espécie na área se dá por conta que a mesma destaca-se em comunidades de sucessão secundárias, ou seja, em áreas que houve intervenção humana (agricultura e/ou pecuária). Outra justificativa pode estar relacionada à grande capacidade de rebrota que é uma resposta fisiológica da espécie em prol do distúrbio dessa espécie após sofrerem algum tipo de perturbação.

Quando analisado de forma minuciosa esses valores expressam o quanto homogêneo é o fragmento estudado, sendo que uma ou poucas espécies dominam o ambiente em questão. 


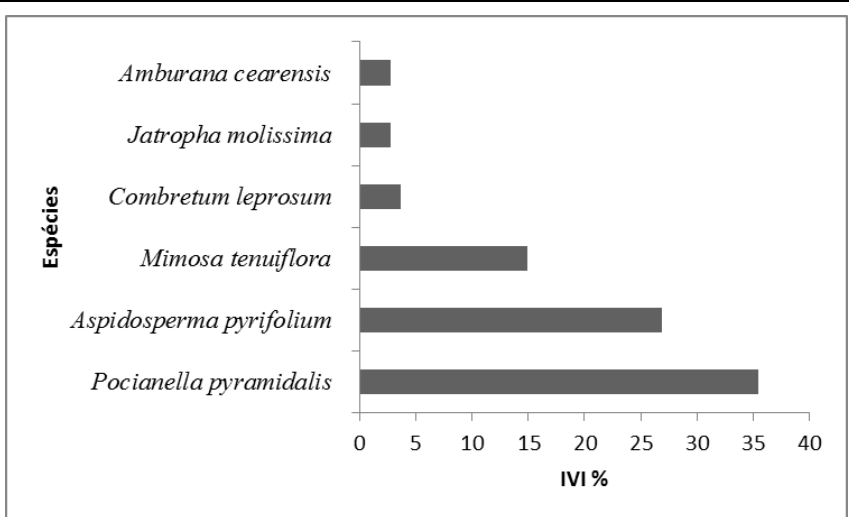

Figura 03 - Espécies com os maiores valores de importância (IVI), amostrados em fragmento de caatinga na Fazenda Massapê, município de São Mamede-PB.

A Aspidosperma pyrifolium obteve o segundo maior valor para densidade relativa $(33,88 \%)$ e o primeiro valor para a frequência relativa $(17,39 \%)$. Em relação ao valor de dominância relativa, a mesma apresentou (29,37\%), sendo assim, considerada a segunda espécie com o maior IVI observado.

As espécies, Pocianella pyramidalis, Aspidosperma pyrifolium, Mimosa tenuiflora, Combretum leprosum, Jatropha molissima , Ximenia intermedia foram as que apresentaram os maiores IVI, representando $86 \%$ do IVI total (Figura 03). O Índice de Valor de Importância constitui um parâmetro de integração dos aspectos parciais, de forma a combiná-los em uma única e simples expressão, somando-se, para cada espécie, os valores relativos da densidade, frequência e dominância, expondo a importância ecológica relativa de cada espécie.

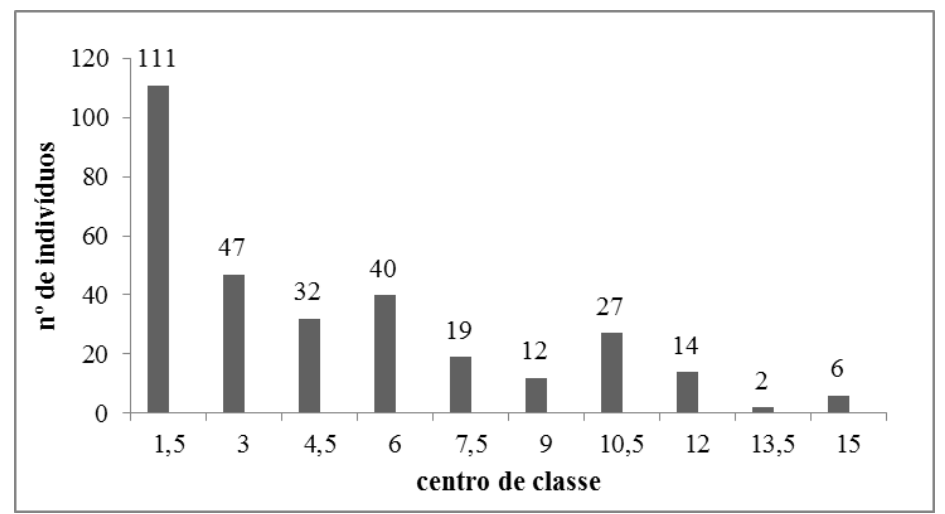

Figura 04 - Número de indivíduos em classes de altura amostradas em fragmento de caatinga na Fazenda Massapê, município de São Mamede-PB.

Em se tratando de distribuição por classe de altura, pode-se se constatar que as classes com os maiores números de indivíduos foram da primeira a quarta classe, totalizando $75 \%$ do número de indivíduos amostrados. A primeira classe foi a que deteve o maior número de indivíduos (111), significando dizer que a floresta apresenta na sua maioria indivíduos de pequeno porte com altura que vai de 2-4 m. (Figura 04).

A altura média dos indivíduos inventariadas foi de $3,6 \mathrm{~m}$ e este valor foi semelhante aos verificados por Alves et al. (2013), que analisaram a estrutura vegetacional em uma área de Caatinga no município de Bom Jesus, PI e obteve o valor de $3,44 \mathrm{~m} \mathrm{e}$ inferior ao observado por Lima e Coelho (2015), que estudando a estrutura do componente arbustoarbóreo de um remanescente de Caatinga no estado do Ceará obtiveram uma altura média de $5,2 \mathrm{~m}$.
Alves et al. (2013) ressaltam que o grau de perturbação verificado em algumas área de estudos pode ser um fator que influencia diretamente a baixa altura média das espécies nessas comunidades, então o valor na área de estudo e nos trabalhos citados, foi um fator predominante para a baixa altura média nessas comunidade. Quanto à distribuição diamétrica foi encontrado 92 indivíduos na primeira classe de diâmetro correspondendo a $30 \%$ do total de indivíduos amostrados; na segunda classe cerca de 67 indivíduos estão presentes o que corresponde a $22 \%$ do número total e a terceira classe apresentou 48 e $15 \%$ do número total (Figura 05). A predominância de indivíduos nas primeiras classes de diâmetro, apresentando padrão de J invertido, enfatiza o padrão normal para floresta inequiâneas (ALVES et al., 2013; LIMA; COELHO, 2015). 


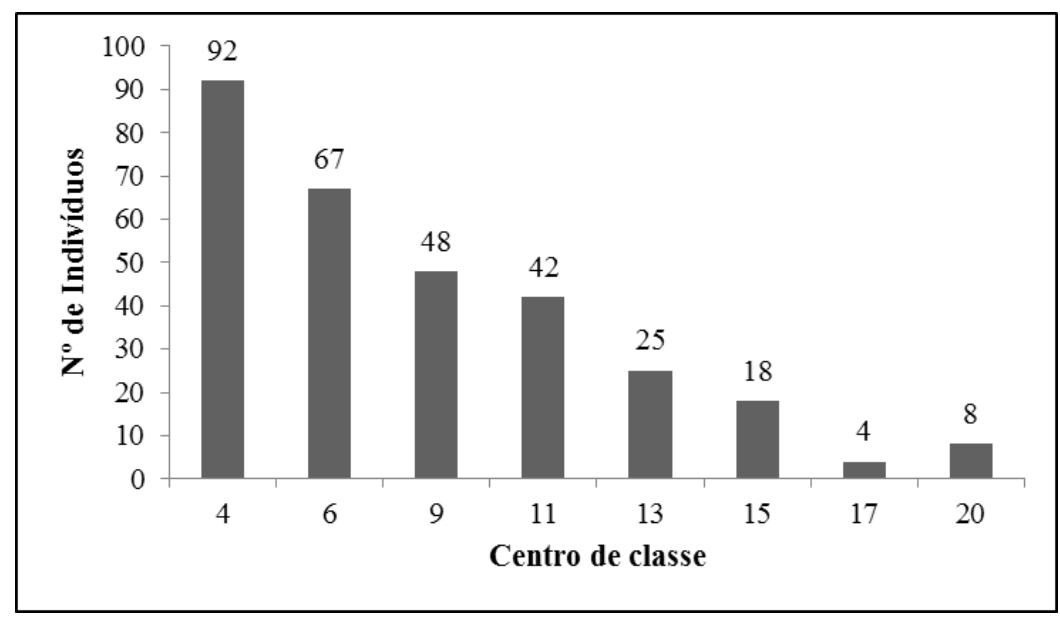

Figura 05 - Número de indivíduos em classes de diâmetros em fragmento de caatinga na Fazenda Massapê, município de São Mamede-PB.

Quanto ao índice de diversidade de ShannonWeaver $\left(\mathrm{H}^{\prime}\right)$ observado para a área de estudo, este corresponde a 1,47 nats.ind ${ }^{-1}$, valor semelhante aos verificados por Holanda et al. (2015), de 0,23 e 1,50 nats.ind $^{-1}$, os quais estudaram a estrutura da vegetação em remanescentes de caatinga com diferentes históricos de perturbação no município de Cajazeirinhas (PB).

No entanto foi inferior ao levantamento feito por Ferraz et al., (2014), que analisaram a estrutura do componente arbustivo-arbóreo da vegetação em duas áreas de caatinga, no município de Floresta, Pernambuco, onde obtiveram 2,10 nats.ind ${ }^{-1}$ e por Marangon et al., (2013) que analisaram a estrutura e padrão espacial da vegetação em uma área de Caatinga e constataram, 2.11 nats.ind $^{-1}$. A comparação de diferentes áreas de caatinga por meio de índices de diversidade deve ser feita de maneira cautelosa, já que os índices sofrem influência de fatores bióticos e abióticos, critérios de inclusão, nível e tempo de antropismo.

De modo geral, o valor encontrado neste trabalho é considerado baixo para o padrão de diversidade conhecido para a Caatinga, dessa forma a degradação do bioma mais uma vez é demonstrado através de estudo florístico como é o caso do presente levantamento. Assim pode-se perceber que a área estudada está em processo de recuperação, e o manejo adequado deste fragmento é de fundamental importância, para garantir e assegurar a biodiversidade existente nesse bioma.

O valor calculado para o Índice de Dominância de Simpson (C) observado neste estudo foi de 0,31, sendo considerado inferior quando comparado com a maior parte dos levantamentos aqui observados, ganhando destaque, o encontrado por Morangon et al. (2013) com valor 0,84 Indice de Dominância de Simpson, Indice de Dominância de Simpson 0,99 que foi encontrado por Leite et al. (2015).
O índice de equabilidade de Pielou (J') obtido foi de 0,55 , o que há uma única ou poucas espécies que predominem sobre as outras, ou seja, quanto menor este valor, menor é a diversidade e maior é a dominância de uma ou poucas espécies. O valor encontrado neste estudo foi semelhante aos encontrados por Calixto Junior e Drumond (2014), que analisando e comparando dois fragmentos de Caatinga em Petrolina, PE, encontraram valores de 0,50 e 0,78 . No entanto apresentou valor inferior aos observados por Leitão et al. (2014), que encontraram um valor de 0,89 .

Quando analisados em conjunto esses índices demonstram com seguridade a real diversidade de um determinado fragmento, assim como já evidenciado os dados aqui expressos justificam e alertam para a degradação sofrida pelo fragmento florestal estudado. Marangon et al, (2013) reforça que geralmente, estudos nesse bioma não demonstram diversidades muito elevadas, assim percebe-se, no presente estudo, uma baixa diversidade. Esse fato se dá provavelmente por fatores principalmente no que diz respeito ao solo, baixa precipitação e principalmente pelos histórico de uso e ocupação do solo.

\subsection{Modelagem da distribuição diamétrica}

Os resultados dos ajustes realizados considerando todas as espécies do remanescente em estudo, bem como para as espécies que apresentaram maior (VI), Pocianella pyramidalis, Aspidosperma pyrifolium e Mimosa tenuiflora, estão representados na (Tabela 04). 
Tabela 04: Parâmetro das distribuições de densidade de probabilidade para todas as espécies estudadas.

\begin{tabular}{|c|c|c|c|c|c|c|c|c|c|}
\hline \multirow{2}{*}{ Espécie } & \multirow{2}{*}{ Modelo } & \multicolumn{5}{|c|}{ Coeficientes } & \multirow{2}{*}{ AIC } & \multirow{2}{*}{ Ranking } & \multirow{2}{*}{ dAIC } \\
\hline & & $\mu$ & $\sigma$ & $\beta$ & $\gamma$ & $\alpha$ & & & \\
\hline \multirow{5}{*}{ Todas espécies } & Weibull 3P & - & - & 5,01645 & 1,1461 & 2,9969 & 2123,195 & $1^{\circ}$ & $0 *$ \\
\hline & Log-normal & 1,9287 & 0,4886 & - & - & - & 2188,218 & $2^{\circ}$ & 65 \\
\hline & Gama & - & - & 0,5445 & 4,2363 & - & 2215,743 & $3^{\circ}$ & 92,5 \\
\hline & Weibull 2P & - & - & 8,8323 & 2,0609 & - & 2261,754 & $4^{\circ}$ & 138,6 \\
\hline & Normal & 7,7783 & 4,0533 & - & - & - & 2343,334 & $5^{\circ}$ & 220,1 \\
\hline \multirow{5}{*}{$\begin{array}{l}\text { Pocianella } \\
\text { pyramidalis }\end{array}$} & Weibull 3P & - & - & 6,0823 & 1,3657 & 3,0795 & 702,059 & $1^{\circ}$ & 0 \\
\hline & Log-normal & 2,0568 & 0,4607 & - & - & - & 711,6202 & $2^{\circ}$ & 9,6 \\
\hline & Gama & - & - & 0,5781 & 5,0123 & - & 712,178 & $3^{\circ}$ & 10,1 \\
\hline & Weibull 2P & - & - & 9,8143 & 2,3575 & - & 720,4286 & $4^{\circ}$ & 18,4 \\
\hline & Normal & 8,6702 & 3,9284 & - & - & - & 734,24 & $5^{\circ}$ & 32,2 \\
\hline \multirow{5}{*}{$\begin{array}{c}\text { Aspidosperma } \\
\text { pyrifolium }\end{array}$} & Weibull 3P & - & - & 4,6993 & 1,0888 & 2,9947 & 523,0017 & $1^{\circ}$ & 0 \\
\hline & Log-normal & 1,8962 & 0,4873 & - & - & - & 539,1686 & $2^{\circ}$ & 16,2 \\
\hline & Gama & - & - & 0,5514 & 4,1623 & - & 548,4815 & $3^{\circ}$ & 25,5 \\
\hline & Weibull 2P & - & - & 8,5725 & 1,9946 & - & 562,1501 & $4^{\circ}$ & 39,1 \\
\hline & Normal & 7,5475 & 4,0767 & - & - & - & 585,8994 & $5^{\circ}$ & 62,9 \\
\hline \multirow{5}{*}{ Mimosa tenuiflora } & Gama & - & - & 0,4446 & 4,5587 & - & 213,5669 & $1^{\circ}$ & $0 *$ \\
\hline & Weibull 3P & - & - & 8,3904 & 1,5775 & 2,6956 & 214,1286 & $2^{\circ}$ & $0,6^{*}$ \\
\hline & Log-normal & 2,2139 & 0,4915 & - & - & - & 214,4307 & $3^{\circ}$ & $0,9^{*}$ \\
\hline & Weibull 2P & - & - & 11,6082 & 2,2954 & - & 214,8799 & $4^{\circ}$ & $1,3 *$ \\
\hline & Normal & 10,2527 & 4,7733 & - & - & - & 218,7028 & $5^{\circ}$ & 5,1 \\
\hline
\end{tabular}

*=significativo, $\mu$ - média aritmética; $\sigma$ - desvio padrão; $\alpha=$ Parâmetro de locação; $\beta=$ parâmetro de escala, $\gamma=$ parâmetro de forma. $\mathrm{AIC}=$ Critério de Informação de Akaike. dAIC= Diferença AIC entre dois modelos.

Por meio da análise da distribuição diamétrica (Figura 05), para todas as espécies, bem como para as espécies de maior (VI) é possível verificar que a frequência observada se apresentou de forma decrescente, em que grande parte dos indivíduos se concentra nas menores classes de diâmetro, o que é típico de uma floresta nativa (Campos e Leite, 2013). Estes resultados indicam predominância no estrato inferior de árvores baixas e com pequenos diâmetros no fragmento de Caatinga.

A distribuição diamétrica apresentadas pelas espécies aqui evidenciadas é o esperado para remanescentes florestais nativos, tendo em vista que quanto maior for o número de indivíduos nas classes menores maior é a possibilidade dele fazer-se presente na comunidade adulta.

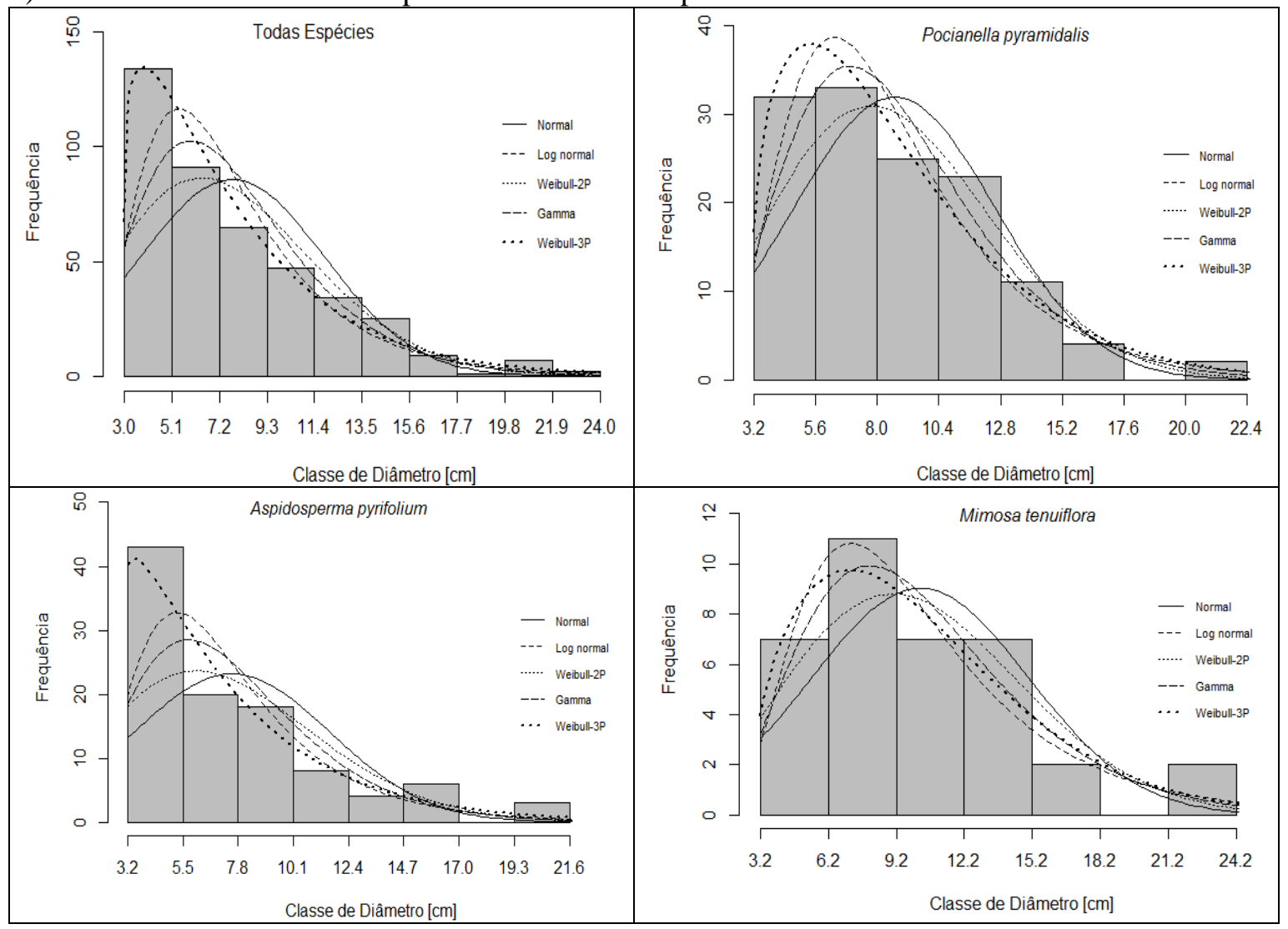

Figura 05 - Distribuição diamétrica para todas as espécies estudadas e para as três espécies de maior (IVI), com suas respectivas frequências observadas e estimadas pelas fdp's. 
Os valores obtidos pelo critério de (AIC) e a diferença dessa estatística entre os modelos (dAIC), estão representados na (Tabela 04), observou-se que a função de Weibull com três parâmetros apresentou aderência para todas as espécies estudadas e para as espécies de maior (IVI), apresentando os menores resultados do critério de (AIC) para todas as espécies (AIC $=2123,195$ ), Pocianella pyramidalis $(\mathrm{AIC}=702,059)$ e Aspidosperma pyrifolium (AIC=523,0017), os resultados aqui encontrados corroboram com o único estudo de modelagem de distribuição diamétrica encontrado na literatura com espécies do bioma Caatinga realizado por Marangon et al, (2016).

Para a espécie Mimosa tenuiflora a função Gamma, apresentou o menor resultado pelo critério de $\quad(A I C=213,5669)$, sendo que esta função apresentou maior acurácia de ajuste apenas para essa espécie. Segundo Burnham e Anderson (2002), para determinar quais os modelos mais acurados é necessário calcular a diferença de AIC entre dois modelos (dAIC), desde que a diferença entre dois modelos seja menor que dois (2), ambos são considerados plausíveis. Com base nesse critério (dAIC<2), apenas a função de Weibuul com três parâmetros foi aderente para todas as espécies, Pocianella pyramidalis e Aspidosperma pyrifolium, as funções Gamma, Normal, Log-normal e Weibull com dois parâmetros apresentaram diferença de AIC superior a dois, (dAIC>2). Para a espécie Mimosa tenuiflora as funções Gamma, Log-normal, Weibull com dois e três parâmetros apresentaram diferença de AIC menor que dois, $(\mathrm{dAIC}<2)$, ambos considerados plausíveis para estimar a distribuição diamétrica da espécie.

Segundo Scolforo (2006), na ciência florestal, a função de distribuição de probabilidade Weibull tem sido amplamente utilizada para descrever a distribuição de diâmetros, tanto em povoamentos equiâneos como inequiâneos. Tem sido utilizada por diversos pesquisadores em seus estudos com adequado desempenho para estimativa da distribuição diamétrica de florestas nativas.

No Brasil, vários estudos têm sido desenvolvidos com aplicação das funções densidade probabilidade em florestas inequiâneas. Diversos autores têm desenvolvido seus trabalhos com o intuito de modelar a distribuição diamétrica para auxiliar na tomada de decisões sobre o manejo e conservação das florestas, dentre outros, pode se destacar os trabalhos de Orellana et al. (2014), Téo et al. (2015), Ebling et al. (2014), estudando fragmentos de floresta ombrófila mista em diferentes regiões do estado do Paraná, Santos et al. (2016), estudando a distribuição diamétrica de uma floresta ombrófila densa de terra firme no estado do Amapá, Marangon et al. (2016), estudando a distribuição diamétrica de espécies lenhosas da Caatinga no semiárido Pernambucano. Todos esses autores recomendaram a função de Weibull com três parâmetros para estimativa da distribuição diamétrica. Resultados semelhantes aos encontrados neste estudo para o remanescente de Caatinga.

As curvas de distribuição diamétrica estimadas e observadas podem ser visualizadas, na (Figura 05), sendo possível observar de forma mais clara o comportamento dos ajustes dos modelos. Observa-se que a função Weibull $3 \mathrm{p}$ apresentou maior flexibilidade ao conjunto de dados, confirmando os resultados obtidos pelo critério de (AIC).

Considerando o critério de avaliação de desempenho dos modelos de densidade probabilidade, (AIC) e (dAIC), os modelos que apresentaram melhor acurácia de ajuste para estimativa da distribuição diamétrica de todas as espécies e para aquelas de maior (VI) foi Weibull com três parâmetros. As funções Gamma, Lognormal e Weibull com dois parâmetros foram aderentes apenas para a espécie Mimosa tenuiflora. Portanto, são adequados para representar a distribuição diamétrica do remanescente de Caatinga, assim como para as espécies que apresentaram os maiores valores de (VI) e auxiliar na tomada de decisões de manejo e conservação das espécies estudadas.

Neste sentido, trabalhos como este devem ser realizados constantemente visando analisar a florística, estrutura vegetacional, estado de conservação, bem como, introduzir e avaliar a eficiência de funções densidade de probabilidade para a descrição da distribuição diamétrica de florestas inequiâneas.

\section{CONCLUSÕES}

A distribuição diamétrica para o remanescente de Caatinga apresentou-se de maneira decrescente, ou seja, exponencial negativa, com maior concentração de indivíduos nas menores classes de diâmetro e com menor concentração nas classes superiores.

A função Weibull com três parâmetros apresentou aderência para todas as espécies estudadas e para as de maior (IVI) gerando estimativas consistentes e pode ser indicada para descrever a distribuição diamétrica e auxiliar na tomada de decisões sobre o manejo e conservação das espécies.

As espécies que assumem maior importância na área de estudo sob os aspectos fitossociológicos foram Pocianella pyramidalis, Aspidosperma pyrifolium, Mimosa tenuiflora, Combretum leprosum, Jatropha molissima , Ximenia intermedia. 
A diversidade de espécies é considerada baixa se comparada com outros fragmentos florestais de caatinga já estudados.

\section{RERERÊNCIAS}

ALVARES, C. A.; STAPE, J. L.; SENTELHAS, P. C.; GONÇALVES, J. L. de M.; SPAROVEK, G. Köppen's climate classification map for Brazil. Meteorologische Zeitschrift, v. 22, 711-728, 2014.

AESA - Agência Executiva de Gestão das Águas do Estado da Paraíba. Mapa interativo. AESA, 2010. Disponível em: <http://www.aesa.pb.gov.br/geoprocessamento/geoportal/ sigaesaweb.html>.

ALVES, A. R. et al. Análise da estrutura vegetacional em umaárea de caatingano municípiode bom jesus, piauí. Revista Caatinga, Mossoró, v. 26, n. 4, p. 99-106, OutDez 2013.

ALVES, L. L. B., ALVES, A. R., BARRETO, F. R. S., HOLANDA, A. C. Análise florística e estrutural de uma área de caatinga preservada no município de Mossoró/R. Conex. Ci. e Tecnol. Fortaleza/CE, v. 11, n. 1, p. 8 - 15, mar. 2017.

APG III. An update of the Angiosperm Phylogeny Group classification for the orders and families of flowering plants: APG II. Botanical Journal of the Linnean Society, v.141, p. 399-436, 2011.

AKAIKE, H. Information theory and an extension of the maximum likelihood principle. In: Petrov, B.N. \& Csaki, F. (eds) Second International Symposium on information theory, pp. 267-281. 1973. Akademiai Kiado, Budapest, HU.

BRASIL. Ministério do Meio Ambiente (MMA). Biomas, Caatinga. Brasília, 2017. Disponível em: <http://www.mma.gov.br/biomas/caatinga >.

BRASIL. Ministério de Minas e Energia. Serviço Geológico do Brasil. Projeto cadastro de fontes de abastecimento por água subterrânea: Paraíba: diagnóstico do município de São Mamede Recife: CPRM/PRODEEM, 10 p. 2005.

BURNHAM, K.P.; ANDERSON, D.R. 2002. Model selection and multi-model inference: a practical information theoretic approach, 2 ed. Springer, New York.

BULHÕES, A.A.; CHAVES, A.D.C.G.; ALMEIDA, R.R.P.; RAMOS, I.A.N.; SILVA, R.A.; ANDRADE, A.B.A.; SILVA, F.T. Levantamento Florístico e Fitossociológico das Espécies Arbóreas do Bioma Caatinga realizado na Fazenda Várzea da Fé no Município de Pombal-PB. Intesa, v. 9, n. 1, p. $51-56$, 2015.
CALIXTO JÚNIOR, J. T.; DRUMOND, M. A. Estudo comparativo da estrutura fitossociológica de dois fragmentos de Caatinga em níveis diferentes de conservação. Pesquisa Florestal Brasileira, Colombo, v. 34, n. 80, p. 345-355, out-dez 2014.

CAMPOS, J. C. C., LEITE H. G. Mensuração florestal: perguntas e respostas. 2013. 4. ed. Viçosa: UFV.

CHAVES, A.D.C.G.; SANTOS, R.M.S.; SANTOS, J.O.; FERNANDES, A.A.; MARACAJÁ, P.B. ACSA Agropecuária Científica no Semiárido, v. 9, n. 2, p. 43 $-48,2013$.

HOLANDA, A. C.; LIMA, F. T. D.; SILVA, B. M.; DOURADO, R. G.; ALVES, A. R. . Estrutura da vegetação em remanescentes de caatinga com diferentes históricos de perturbação em Cajazeirinhas (PB). Revista Caatinga (Online), v. 28, p. 142-150, 2015.

EBLING, A. A.; PELISSARI, A. L.; ABRAO, S. F.; BAMBERG, R. Prognose da estrutura diamétrica de remanescente de floresta com Araucária utilizando a função densidade de probabilidade Weibull. Agroambiente, v. 8, p. 112-118, 2014.

FELFILI, J. M.; REZENDE, R. P. Conceitos e Métodos em Fitossociologia. Brasília: UnB, Departamento de Engenharia Florestal, 2003. 68 p. (Comunicações Técnicas Florestais).

FERRAZ, R. C. et al. Levantamento fitossociológico em área de caatinga no monumento natural grota do angico , Sergipe, Brasil. Caatinga, Mossoró, v. 26, n. 3, p. 89-98, Jul-Set 2013.

FERRAZ, J. S. F.; FERREIRA, R. L. C.; SILVA, J. A. A.; MEUNIER, I. M. J.; SANTOS, M. V. F. Estrutura do componente arbustivo-arbóreo da vegetação em duas áreas de caatinga, no município de floresta, Pernambuco. Revista Árvore, Viçosa, v.38, n.6, p.1055-1064, 2014.

KUCHLA, W. J.; STEPKA, T. F.; SAWCZUK, A. R.; LISBOA, G. S. Florística, estrutura horizontal e distribuição diamétrica em área de transição de Cerrado e Floresta Aluvial no município de Campos de Júlio-MT. Ambiência (UNICENTRO). v. 11, p. 13-30, 2015.

LEITE, J.A.N.; ARAÚJO, L.V.C.; ARRIEL, E.F.; CHAVES, L.F.C.; NÓBREGA, A.M.F. Análise quantitativa da vegetação lenhosa da Caatinga em Teixeira, PB. Pesq. flor. bras., Colombo, v. 35, n. 82, p. 89-100, abr./jun. 2015.

LEITÃO, A.C., VASCONCELOS, W. A., CAVALCANTE, A. M. B. TINOCO, L. B. M., FRAGA, V. S. Florística e estrutura de um ambiente transicional Caatinga-Mata Attântica, Revista Caatinga, Mossoró, v. 27, n. 3, p. $200-210$, jul. - set. 2014.

LIMA, B. G. Caatinga: espécies lenhosas e herbáceas. Mossoró: Ed. UFERSA, 2012. 316 p. 
LIMA, B. G.; COELHO, M. F. B. Estrutura do componente arbustivo-arbóreo de um remanescente de Caatinga no estado do Ceará, Brasil. Cerne, v. 21, n. 4, p. 665-672, Janeiro 2015.

LORENZI, H. Árvores brasileiras: manual de identificação e cultivo de plantas arbóreas nativas do Brasil. 4 ed. Nova Odessa, São Paulo: Instituo Plantarum, 2002. 368 p. v.1.

MAIA, G. N. Caatinga: árvores e arbustos e suas utilidades. 2. ed. Fortaleza, Printcolor Gráfica e Editora, 2012. 413 p.

MARANGON, G. P. et al. Estrutura e padrão espacial da vegetação em uma área de Caatinga. Floresta, Curitiba, v. 43, n. 1, p. 83-92, jan-mar 2013.

MARANGON, Gabriel Paes; FERREIRA, R. L. C. ; SILVA, J. A. A. ; Schneider, P. R. ; LOUREIRO, G.H. . Modelagem da distribuição diamétrica de espécies lenhosas da Caatinga, Semiárido Pernambucano. Ciência Florestal (UFSM. Impresso), v. 26, p. 863-874, 2016.

MONTEIRO, E. R.; MANGOLIN, C. A.; NEVES, A. F. das; ORASMO, G. R.; SILVA, J. G. M. da; MACHADO, M. F. P. S. Genetic diversity and structure of populations in Pilosocereus gounellei (F.A.C.Weber ex K.Schum.) (Cactaceae) in the Caatinga biome as revealed by heterologous microsatellite primers. Biochemical Systematics and Ecology, Oxford, v. 58, n. 2, p. 7-12, 2015.

MOREIRA, A. R. P. et al., Composição Florística e análise Fitossociológica Arbustivo-arbóreo no município de Caraúbas-RN. Revista verde (Mossoró - RN Brasil), v.2, n.1, p. 113-126, Janeiro/Julho de 2007.

ORELLANA, E.; FIGUEIREDO FILHO, A.; NETTO, S. P.; DIAS, A. N. Modelagem da distribuição diamétrica de espécies florestais em um fragmento de floresta ombrófila mista. Revista Árvore. v. 38, p. 297-308, 2014.

RAMALHO, C. I.; ANDRADE, A. P. de; FÉLIX, L. P.; LACERDA, A. V. de; MARACAJÁ, P. B. Flora arbóreoarbustiva em áreas de Caatinga no Semi-Árido baiano,
Brasil. Revista Caatinga, Mossoró, v. 22, n. 3, p. 182190, 2009.

R CORE TEAM. R: A language and environment for statistical computing. $\mathrm{R}$ Foundation for Statistical Computing, Vienna, Austria. 2015. URL https://www.Rproject.org/.

RODAL, M. J. N.; COSTA, K. C. C.; SILVA, A. C. B. e. Estrutura da vegetação caducifólia espinhosa (Caatinga) de uma área do sertão central de Pernambuco. Hoehnea, São Paulo, v. 35, n. 2, p. 209-217, 2008.

SANTANA, J.A.S. Estrutura Fitossociológica, produção de serapilheira e ciclagem de nutrientes em uma área de caatinga no Seridó do Rio Grande do Norte. 2005. 206 p. Tese (Doutorado em Agronomia) Universidade Federal da Paraíba, Paraíba, 2005.

SANTOS, R. O.; ABREU, J. C.; LIMA, R. B.; APARÍCIO, P. S.; SOTTA, E. D.; LIMA, R. C. Distribuição diamétrica de uma comunidade arbórea na Floresta Estadual do Amapá, Brasil. Biota Amazônia, Vol. 6, Ed. 2, Pág. 24-31, 2016.

SAMPAIO, E. V. S. B.; PAREYN, F. G. C.; FIGUEIRÔA, J. M.; SANTOS JUNIOR, A. G. S. (Eds.). Espécies da flora nordestina de importância econômica potencial. Recife: Associação Plantas do Nordeste, 2005. 331p.

SCOLFORO, J. R. S. Biometria florestal. Lavras: UFLA/FAEPE, 2005. 352 p.

SOARES, C. P. B.; PAULA NETO, F.; SOUZA, A. L. Dendrometria e Inventário Florestal. 1 ed. Viçosa: Editora UFV, 2009. 276 p. (segunda reimpressão).

STURGES, H. A. The choice of a class interval. Journal of the American Statistical Association. v. 21, n. 153, p. 65-66, 1996.

TÉO, S. J.; MARCON, F.; SCHNEIDER, C. R.; SANTOS, F. B.; CHIARELLO, K. M. A.; FIORENTIN,

L. D. modelagem da distribuição diamétrica de um fragmento de floresta ombrófila mista em Lebon Régis, SC. Floresta (online) (curitiba), v. 45, p. 337-348, 2015. 